\title{
Special Issue on Music and Shape
}

DANIEL LEECH-WILKINSON

King's College London

MATS B. KÜSSNER

King's College London

THIS is the third of the three-part volume on relationships between music and shape. The earlier issues on the themes of Pedagogy and Performance (Vol. 8, No. 1), and Motion Shapes (Vol. 8, No. 2) are complemented here by a focus on Perception and Theory. Topics addressed include cross-cultural representations of musical shapes from the UK, Japan and Papua New Guinea; the evolutionary origins of tonality as a system for the dynamic shaping of affect; and how shaping and co-shaping of 'forms of vitality' in music gives rise to aesthetic experience. 